\title{
Differential Gene Expression Pattern of Transforming Growth Factor Beta- 1 in Early and Advanced Breast Cancers
}

Heena V Dave*, Manoj J Shah, Shilin N Shukla and Sunil N Trivedi

The Gujarat Cancer \& Research Institute, Gujarat, India

\begin{abstract}
Background: Transforming Growth Factor Bs (TGF- $\beta$ s) are pluripotent polypeptides that switch function from growth suppressor to promoter during breast tumorigenesis. This integral function in tumor progression offers it as an attractive target of cancer therapy. Amongst the three mammalian isoforms, TGF- $\beta 1$ is the most potent, abundant and is considered to be the representative of TGF- $\beta$ pathway. Higher circulating TGF- $\beta 1$ is known to affect prognosis, increase relative risk of recurrence and reduced survival in breast cancer. Altered gene expression is determined in breast cancer cell lines; however it is less explored in clinical breast cancer.
\end{abstract}

Methods: We investigated expression of TGF- $\beta 1$ with an aim to explore its utility as biomarker. TGF- $\beta 1$ gene expression was determined from breast cancer patients $(\mathrm{N}=118)$ using Real-Time PCR. The relative quantitation was determined by ddct method and differences were expressed as mean fold change (MFC) using GAPDH as endogenous control and adjacent normal tissue of each patient as calibrator. TGF- $\beta 1$ gene expression was correlated with clinicopathologic prognosticators. Relapse-free and overall survival were assessed by Kaplan-Meier Survival analysis with log-rank test.

Results: TGF- $\beta 1$ mRNA was downregulated in early stage tumors (1.46 fold) whereas it was upregulated in advanced stage tumors (1.60 fold; $p=0.05)$. Higher downregulation was seen in perimenopausal- than postmenopausal- patients $(p=0.022)$. Node positive and node negative patients exhibited differences in early and advanced tumors $(p=0.00001)$. Ductal carcinoma showed highest downregulation however, linear correlation was seen with grade+++ stromal involvement. Reduced disease-free survival (DFS) was noted in tumors with downregulation and advanced stage than early stage patients.

Conclusion: We conclude that downregulation of TGF- $\beta 1$ is associated with poor disease-free survival. TGF- $\beta 1$ may play a significant role in the invasiveness and metastatic potential of breast cancer. The magnitude of downregulation is believed to be responsible for disease progression and can be used as predictive and prognostic marker.

Keywords: Human Breast cancer; TGF- $\beta 1$ mRNA; Real-Time PCR; Prognosis; Survival

\section{Introduction}

Transforming Growth Factor Beta (TGF- $\beta$ ) represents a large family of polypeptides believed to regulate diverse cellular processes like cell proliferation, differentiation, cell motility and adhesion [1]. The actions of TGF- $\beta$ signaling are mediated soon after the ligands reach to the membrane and bind directly to TGF $\beta$ receptor type II (TßRII), which transphosphorylate the type I receptor (TßRI), enabling the phosphorylation of T $\beta$ RI kinase domain which propels downstream signaling actions through SMAD proteins [2]. TGF- $\beta$ signaling is thought to be tissue-context and ligand content-dependent. Signals induced by TGF-1 are important for growth and development of normal mammary gland development as well as for mammary tumorigenesis $[3,4]$. In breast cancer pathogenesis, growth-inhibitory effects of TGF- $\beta$ are featured at early stages of carcinogenesis; however these effects shift to growth-promoting effects with more advanced malignant states [5].

Amongst three mammalian isoforms, TGF- $\beta 1$ is the first ligand derived from induced growth of anchorage-independent mouse fibroblasts and is reported as an imperative growth regulator of epithelial cells including mammary gland [6]. TGF- $\beta$ superfamily is comprised of about $60-70$ structurally related proteins where TGF- $\beta 1$ is a prototype of the family. Till date, TGF- $\beta 1$ is the only and best characterized isoform amongst all [7]. All three ligands (TGF- $\beta 1$, TGF- $\beta 2$, TGF- $\beta 3$ ) are encoded by unique genes located on various chromosomes; however they share $64 \%$ to $85 \%$ amino acid sequence homology [8] amongst which, TGF- $\beta 1$ gene is located on chromosome $19 \mathrm{q} 13$ and is expressed as a $25-\mathrm{kDa}$ protein [9].

Majority of studies performed on circulatory TGF- $\beta 1$ show that higher TGF- $\beta 1$ was connected to poor prognosis and a progressive disease in many malignancies like breast [10], prostate [11] and hepatocellular carcinoma [12]. Higher serum levels of TGF- $\beta 1$ shorten overall survival of breast cancer patients $[13,14]$. Circulating TGF- $\beta 1$ was higher in breast cancer patients than healthy individuals; moreover, an increase was seen with advancing stage provoking the shift in its biological role from growth inhibitor to promoter $[15,16]$ Prognostic utility of TGF- $\beta 1$ was evaluated from breast cancer cell lines [17] or studies that measured circulatory levels $[18,19]$. However, very few reports are available where tumoral TGF- $\beta 1$ either at protein or mRNA level was estimated from clinical human breast cancer. Role of

*Corresponding author: Heena V Dave, PhD, The Gujarat Cancer \& Research Institute, Ahmedabad, Gujarat, India, E-mail: dave_heena@hotmail.com

Received October 25, 2011; Accepted November 22, 2011; Published November 24, 2011

Citation: Dave HV, Shah MJ, Shukla SN, Trivedi SN (2011) Differential Gene Expression Pattern of Transforming Growth Factor Beta-1 in Early and Advanced Breast Cancers. J Cancer Sci Ther 3: 244-249. doi:10.4172/1948-5956.1000098

Copyright: ( 2011 Dave HV, et al. This is an open-access article distributed unde the terms of the Creative Commons Attribution License, which permits unrestricted use, distribution, and reproduction in any medium, provided the original author and source are credited. 
tumoral TGF- $\beta 1$ with in human breast carcinoma was assessed where strong immunostaining suggested tumor progression and announced a reduced overall survival $[20,21]$. Linear association of TGF- $\beta 1$ with BRCA2 was found to be associated with the prognosis and treatment of breast cancer [22]. Downregulation of TGF- $\beta 1$ mRNA was also reported in breast [23] and cervical cancer [24]. However, TGF- $\beta 1$ mRNA expression in human breast cancer prognosis and its relation to clinicopathologic prognosticators, especially with real time RT-PCR, has not yet been published to the best of our knowledge. The only report on estimation of all three TGF- $\beta$ human isoforms with real time RTPCR was in laryngeal cancer that has shown their utility as molecular markers in distinguishing cancer from non-neoplastic tissues [25]. In the present study, we investigated TGF- $\beta 1$ gene expression and compared its transcript levels with disease progression from early to advanced stage breast cancer. The role of TGF- $\beta 1$ transcript levels was further elucidated by its comparison with clinicopathological prognosticators and survival in breast cancer patients.

\section{Materials and Methods}

\section{Patients and disease outcome}

This prospective study was approved by the Institutional Ethical Committee and informed consent was obtained from each patient. Previously untreated breast cancer patients [ $\mathrm{N}=118]$ were randomly enrolled for this study with a mean age of 47 years (Range: $25-80$ years). Patients with AJCC TNM stage I and IIA were considered as early stage disease $[\mathrm{N}=42]$ and patients with stage IIB or above were considered as advanced stage disease [N=76] [26]. The incidence of clinical factors (Age, Menopausal status) as patient's characteristics and tumor characteristics (Tumor size, Nodal status, Histologic type, Histologic grade and Stromal involvement)] are presented in Table 1. Majority of patients belong to the middle age and postmenopausal groups. Majority of tumors were node positive, having ductal origin, with moderate/ poor differentiation and stromal involvement. Remarkably, majority of tumors were aggressive in origin and may result into faster disease spread with shorter survival. The median follow-up of the patients was
49 months (Range 6-92 months). Till the end of the study, fifty patients (50/118) relapsed amongst whom 11 belong to early stages and 39 were from advanced stages. Moreover, 20 patients died (20/118) from whom 5 had early stage and 15 had advanced stage disease.

\section{Tissues}

Tissues were collected at Modified-Radical Mastectomy (MRM) and synchronous tissues [Tumor ( $\mathrm{T}$ ) and adjacent normal tissues (ANT)] were collected from each patient. Malignant Lymph nodes $(\mathrm{N}=49)$ from node positive patients and non-malignant lymph nodes $(\mathrm{N}=22)$ were also collected. Malignant tissues were selected by the same pathologist to minimize individual bias and tissues with $\geq 90 \%$ tumor cells were selected for the study. All the tissues were collected, scraped off fat and necrotic material and stored in RNA Later (Ambion \#7024). Tissues were pulverized in liquid nitrogen using Mikrodismembrator (B. Braun, Germany) for 5 minutes at $3000 \mathrm{rpm}$ and stored in liquid nitrogen until analysis.

\section{RNA Isolation and purification}

Total RNA was extracted from tumor tissues (50 mg) using RNeasy Tissue Kit (Qiagen \#74106) and from adjacent normal tissues using (100 mg ) RNeasy Lipid Tissue kit (Qiagen\#74804) using manufacturer's instructions. DNase digestion was carried out with RNase-Free DNase set (Qiagen \# 79254) as per manufacturer's instruction. RNA was eluted in RNase-free water. RNA quantitation was performed with spectrophotometer (Multiskan Spectrum, Thermofisher, Finland). Total RNA was then aliquoted and stored at $-70^{\circ} \mathrm{C}$ till further analysis. RNA purity was checked on 1\% FA gel using Mini-Sub-Cell GT (BioRad) with visualization on Gel Documentation System (BioRad GelDoc XR+).

\section{Reverse Transcription and Relative Quantitation of TGF- $\beta 1$ by Real Time Reverse Transcriptase Polymerase chain Reaction (Real Time RT-PCR)}

Five $\mu \mathrm{g}$ total RNA was reverse transcribed using cDNA archive

\begin{tabular}{|c|c|c|c|c|}
\hline Parameter & & Total patients & Early & Advanced \\
\hline & & $\mathrm{N}(\%)$ & $\mathrm{N}(\%)$ & $\mathrm{N}(\%)$ \\
\hline \multirow[t]{3}{*}{ Age (Years) } & $\leq 40$ & $28(23.73)$ & $11(26.19)$ & $17(22.37)$ \\
\hline & $41-60$ & $80(67.80)$ & $28(66.67)$ & $52(68.42)$ \\
\hline & $>60$ & $10(8.47)$ & $03(7.14)$ & $07(9.21)$ \\
\hline \multirow[t]{3}{*}{ Menopausal status } & Premenopausal & $47(39.83)$ & 16(38.09) & $31(40.79)$ \\
\hline & Perimenopausal & 19(16.10) & $03(7.14)$ & $16(21.05)$ \\
\hline & Postmenopausal & $52(44.07)$ & $23(54.76)$ & $29(38.16)$ \\
\hline \multirow[t]{2}{*}{ Nodal status } & Node Negative & $53(44.92)$ & $38(90.48)$ & 15(19.74) \\
\hline & Node positive & $65(55.08)$ & $04(9.52)$ & $61(80.26)$ \\
\hline \multirow[t]{3}{*}{ Histologic Type } & Ductal Carcinoma & 101(85.59) & 35(83.33) & $66(86.84)$ \\
\hline & Lobular Carcinoma & $04(3.39)$ & $02(4.76)$ & $02(2.63)$ \\
\hline & Others & $13(11.02)$ & 05(11.90) & $08(10.52)$ \\
\hline \multirow[t]{2}{*}{ Histologic Grade } & Well Differentiation & $18(15.25)$ & $11(26.19)$ & $07(9.21)$ \\
\hline & $\begin{array}{l}\text { Moderate+poor } \\
\text { Differentiation }\end{array}$ & $100(84.75)$ & $31(73.81)$ & 69(90.79) \\
\hline \multirow[t]{5}{*}{ Stromal Involvement } & Absent & 02(1.69) & 00 & $02(2.63)$ \\
\hline & Present & 116(98.31) & $42(100.0)$ & 74(97.38) \\
\hline & + & $63(54.31)$ & $21(50.00)$ & $42(56.76)$ \\
\hline & ++ & $42(36.21)$ & $15(35.71)$ & $27(36.48)$ \\
\hline & +++ & $11(9.48)$ & $06(14.29)$ & $05(6.76)$ \\
\hline
\end{tabular}

Table 1: Clinical, Pathological characteristics of 118 breast cancer patients. 
kit (Applied Biosystems, Cat \#) using manufacturer's instructions. Real-time quantitative PCR analysis was performed on ABI 7000 sequence detection system (Applied Biosystems) using TaqMan chemistry. Complementary DNA (cDNA) corresponding to $100 \mathrm{ng}$ of total RNA was amplified in a reaction volume of $25 \mu$ containing $2 \mathrm{X}$ TaqMan Universal Master mix (ABI 4304437) as recommended by the manufacturer. Validated primer-probe mixture was purchased from Applied Biosystems (Part \#4331182; TaqMan(R) Gene Expression Assays; (1) TGF- $\beta 1$ : (Hs00171257_m1); (2) ER : (Hs00174860_ m1); (3) GAPDH (Glyceraldehyde 3-phosphate Dehydrogenase : (Hs99999905_ml)]. Universal thermal cycling conditions were observed which comprised of an initial AmpErase UNG activation step at $50^{\circ} \mathrm{C}$ for 2 minutes followed by denaturation step at $95^{\circ} \mathrm{C}$ for 10 minutes and 40 cycles at $95^{\circ} \mathrm{C}$ for 0.15 minutes and $60^{\circ} \mathrm{C}$ for 1 minute. For each patient, the PCR was run in triplicate. The relative expression of the target gene was computed using ddCt method [27] and adjacent non-neoplastic tissue from the same patient as calibrator. The gene expression was expressed as mean fold change (MFC).

\section{Statistical analysis}

Statistical analysis was performed using SPSS for Windows (v13.0). The non-parametric Chi-square test was used to compare fold change with clinicopathological variables. The correlation between different parameters was analysed using the non-parametric Spearman's correlation coefficient. Survival analysis was done with Kaplan-Meier curves using log-rank test. $\mathrm{p}<0.05$ was considered as significant.

\section{Results}

In the present study, we assessed TGF- $\beta 1$ expression in malignantand in non-malignant- adjacent normal tissues using Real-Time PCR and gene expression was quantitated as the fold change using ddct method.

\section{Expression of TGF- $\beta 1$ transcript in the study}

TGF- $\beta 1$ gene was 1.27 fold upregulated in the total cohort of 118 patients. Notably, TGF- $\beta 1$ was significantly downregulated in early stage patients (1.46 fold) whereas it was upregulated in advanced stage patients ( 1.60 fold; $\mathrm{p}=0.05$ ) exhibiting a shift in gene expression. In furtherance, early and advanced stage patients were classified into an upregulation and downregulation of gene expression and all the comparisons were done into four groups: (1) Early stage: Upregulation, (2) Early stage: Downregulation, (3) Advanced stage: Upregulation and (4) Advanced stage: Downregulation. TGF-1 was upregulated in $16.7 \%$ (7/42; 2.03 fold) whereas downregulated in $83.3 \%$ early stage tumors $(35 / 42 ; 2.42$ fold). Amongst advanced tumors, TGF- $\beta 1$ was upregulated in $31.6 \%(24 / 76 ; 4.08$ fold) whereas downregulated in $68.4 \%$ tumors $(52 / 78 ; 2.18$ fold $)$. It has been observed that there was a 2.05 fold increase in the upregulation in $14.9 \%$ of patients from Earlyto Advanced- stages (Figure 1).

\section{Comparison of TGF- $\beta 1$ mRNA expression with clinico- pathological prognosticators}

To establish the prognostic significance of TGF- $\beta 1$ expression in breast cancer, the expression patterns were correlated to several known clinico-pathologic prognosticators (Table 2). Decline in the upregulation was seen with increasing age. An increase of 3.70 fold was seen in advanced stage patients ( 5.03 fold) than early stage patients ( 1.43 fold) in the younger (up to 40 years) patients. Amongst all subgroups, highest upregulation was seen (6.27 fold) in premenopausal patients.

\section{Transcript levels of TGF- $\beta 1$}

$\square$ Early $\square$ Advanced

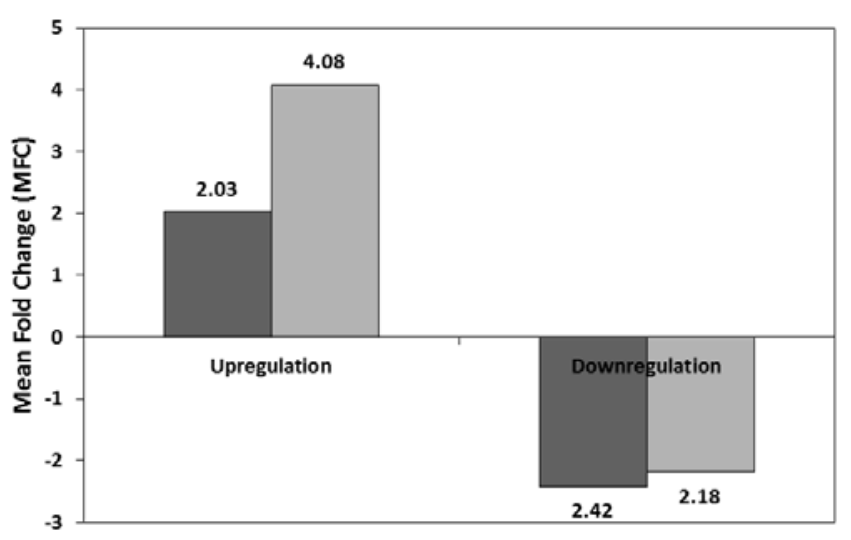

Figure 1: Transcript levels of TGF- $\beta 1$ in Early and Advanced Stages.

Moreover, TGF- $\beta 1$ was downregulated in perimenopausal patients (3.66 fold) than postmenopausal patients ( 2.42 fold) in early stage patients $(p=0.002)$. Node positive and node negative patients exhibited significant downregulation between early versus advanced stages ( $p=0.00001)$. Node negative tumors showed a higher downregulation of TGF- $\beta 1$ in advanced tumors as compared to node positive tumors ( $\mathrm{p}=0.050$; Data not shown).

Though majority of tumors were ductal carcinoma (85.59\%), downregulation of TGF- $\beta 1$ was higher in lobular carcinomas than ductal tumors in advanced stage tumors $(\mathrm{p}=0.036)$. Remarkably, upregulation of TGF- $\beta 1$ exhibited an inverse correlation with different histologic types in early stage patients $[\mathrm{r}=+0.290$; $\mathrm{p}=0.037]$. Histologic Grade and downregulated TGF- $\beta 1$ showed non-uniform pattern between early and advanced stage patients $(\mathrm{p}=0.040)$. Highest downregulation was seen in the grade++ stromal reaction subgroup than grade $+++(p=0.047)$ in early stage patients whereas in advanced stage tumors, it was upregulated in grade +++ group as compared to grade $+(\mathrm{p}=0.009)$ and grade $++(\mathrm{p}=0.02)$. The same observation was also seen in patients with downregulation in grade +++ subgroup than grade $++(\mathrm{p}=0.03)$.

\section{Comparison of expression patterns of TGF- $\beta 1$ and ER $\alpha$}

ERa was evaluated in a subset of 110 patients from the same cohort. It was upregulated in $44.5 \%$ patients (49/110; 7.02 fold) and downregulated in $55.5 \%(61 / 110 ; 3.61$ fold $)$ of patients. On their subgrouping into early- and advanced stage patients, ER $\alpha$ upregulation was evident in $36.7 \%$ patients $(18 / 49 ; 6.52$ fold) and downregulated in $34.4 \%(21 / 61 ; 3.95$ fold $)$. On the other hand, in advanced stage patients ERa was upregulated in $63.3 \%$ ( $31 / 49 ; 7.31$ fold) whereas downregulated in $65.6 \%$ (40/61; 3.44 fold). Then we compared TGF- $\beta 1$ expression amongst all these subgroups. We found a downregulation of TGF- $\beta 1$ in early stage tumors irrespective of ERa up- or down- regulation. Conversely, an upregulation of TGF- $\beta 1$ was seen in advanced stage tumors irrespective of ERa up- or down- regulation (Table 3).

\section{Changes in the expression patterns with disease extension}

TGF- $\beta 1$ was also evaluated from malignant lymph nodes $(\mathrm{N}=49)$ and non-malignant lymph nodes $(\mathrm{N}=22)$ which would show the differences in the gene expression with disease extension to lymph nodes. TGF- $\beta 1$ was upregulated by 1.66 fold in tumor tissues and 
Citation: Dave HV, Shah MJ, Shukla SN, Trivedi SN (2011) Differential Gene Expression Pattern of Transforming Growth Factor Beta-1 in Early and Advanced Breast Cancers. J Cancer Sci Ther 3: 244-249. doi:10.4172/1948-5956.1000098

\begin{tabular}{|c|c|c|c|c|c|c|c|c|c|}
\hline & & \multicolumn{4}{|c|}{ Early } & \multicolumn{4}{|c|}{ Advanced } \\
\hline & & \multicolumn{2}{|c|}{ UP } & \multicolumn{2}{|c|}{ Down } & \multicolumn{2}{|c|}{ UP } & \multicolumn{2}{|c|}{ Down } \\
\hline & & $\mathrm{N}$ & MFC & $\mathrm{N}$ & MFC & $\mathrm{N}$ & MFC & $\mathrm{N}$ & MFC \\
\hline \multirow[t]{3}{*}{ Age(Years) } & $0-40$ & 02 & 1.43 & 09 & 2.94 & 04 & 5.13 & 13 & 2.15 \\
\hline & $41-60$ & 05 & 2.27 & 23 & 2.22 & 19 & 3.99 & 33 & 2.12 \\
\hline & $>60$ & 00 & - & 03 & 2.83 & 01 & 1.44 & 06 & 2.68 \\
\hline \multirow[t]{3}{*}{ Menopausal Status } & PreM & 03 & 1.63 & 13 & 2.30 & 09 & 6.27 & 22 & 2.12 \\
\hline & PeriM & 01 & 2.06 & 02 & $3.66^{*}$ & 06 & 2.29 & 10 & 2.20 \\
\hline & PostM & 03 & 2.42 & 20 & $2.42^{*}$ & 09 & 3.07 & 20 & 2.24 \\
\hline \multirow[t]{2}{*}{ Nodal Status } & $\mathrm{N}_{0}$ & 05 & 2.27 & $33^{\lambda}$ & 2.35 & 06 & 3.24 & $09^{\wedge}$ & 2.39 \\
\hline & $\mathrm{N}_{+}$ & 02 & 1.43 & $02^{\wedge}$ & 4.62 & 18 & 4.35 & $43^{\lambda}$ & 2.14 \\
\hline \multirow[t]{3}{*}{ Histologic Type } & IDC & 06 & 2.03 & 29 & 2.49 & 21 & 3.93 & 45 & $2.05^{\wedge}$ \\
\hline & ILC & 01 & 2.06 & 01 & 4.01 & 00 & - & 02 & $9.61^{\wedge}$ \\
\hline & Others & 00 & - & 05 & 1.95 & 03 & 5.08 & 05 & 2.98 \\
\hline \multirow[t]{2}{*}{ Histologic Grade } & 1 & 01 & 2.31 & $10^{\circ}$ & 2.20 & 02 & 1.26 & $05^{\delta}$ & 1.70 \\
\hline & $\|+I I I$ & 06 & 1.98 & $25^{\circ}$ & 2.51 & 22 & 4.33 & $47^{\circ}$ & 2.25 \\
\hline \multirow[t]{5}{*}{ Stromal Invasiveness } & Absent & 00 & - & 00 & - & 00 & - & 02 & 5.71 \\
\hline & Present & 07 & 2.03 & 35 & 2.42 & 24 & 4.08 & 50 & 2.13 \\
\hline & + & 04 & 2.30 & 17 & 2.59 & 10 & $3.14^{\infty}$ & 32 & 2.15 \\
\hline & ++ & 01 & 1.43 & 14 & $2.60^{\star}$ & 11 & $3.12^{€}$ & 16 & $1.92 *$ \\
\hline & +++ & 02 & 1.79 & 04 & $1.58^{\star}$ & 03 & $10.6^{\infty \epsilon}$ & 02 & $7.24 *$ \\
\hline
\end{tabular}

${ }^{*} \mathrm{p}=0.002, \wedge \mathrm{p}=0.00001 ; \wedge \mathrm{p}=0.036 ; \delta \mathrm{p}=0.040 ; \infty \mathrm{p}=0.009 ; € \mathrm{p}=0.02 ; \star \mathrm{p}=0.047 ; * \mathrm{k}=0.03$

Table 2: Correlation of TGF- $\beta 1$ gene with the clinical and pathological prognosticators.

1.24 fold in their corresponding malignant lymph nodes exhibiting a decrease in the gene expression with disease extension. Moreover, this was compared with the non-malignant lymph nodes (22/49) in which 3 fold increase was noted in non-malignant lymph nodes (4.25 fold; $\mathrm{p}=0.0037$ )

\section{Survival}

TGF $\beta 1$ expression was not affecting the Relapse Free Survival (RFS) in the total cohort $(\mathrm{p}=0.297)$. Amongst the patients who relapsed, a downregulation of TGF- $\beta 1$ transcript was seen in 35/51 (68.6\%) while an upregulation was evident in 16/51 (31.4\%) tumors. Amongst the tumors in which a downregulation of TGF- $\beta 1$ transcript was seen, the patients with advanced stage relapsed earlier than early stage patients ( $\mathrm{p}=0.078$; Figure 2). It was also noticeable that amongst the subgroup of TGF- $\beta 1$ transcript upregulation, $87.5 \%$ patients relapsed who had advanced disease ( $\mathrm{p}=0.219$; Figure 3 ). No differences were seen in the overall survival of the patients in any of the subgroups.

\section{Discussion}

In the current prospective we have estimated TGF- $\beta 1$ mRNA with an aim to explore TGF-Beta signaling switch between early and advanced stage patients and tried to find out its possible role in breast cancer progression. Moreover, TGF- $\beta 1$ mRNA expression was quantitated by highly sensitive real time PCR [27]. Notably, we have used the adjacent normal tissue as calibrator which is obtained from the same patient which would provide the best sample type for comparison. Till date many studies have reported circulating TGF- $\beta 1$

\begin{tabular}{|l|l|l|l|l|l|l|}
\hline & & \multicolumn{4}{|c|}{ TGF- $\beta 1$} \\
\hline & & \multicolumn{3}{|c|}{ Early } & \multicolumn{2}{c|}{ Advanced } \\
\hline & & N & MFC & N & MFC \\
\hline Estrogen Receptor & Upregulation & 18 & 1.61 & 31 & 1.86 \\
\hline & Downregulation & 21 & 1.34 & 40 & 1.14 \\
\hline
\end{tabular}

† MFC : Mean Fold Change

Table 3: Correlation between TGF- $\beta 1$ and Estrogen Receptor $\alpha$.
Downregulation of TGFB1 (GAPDH)

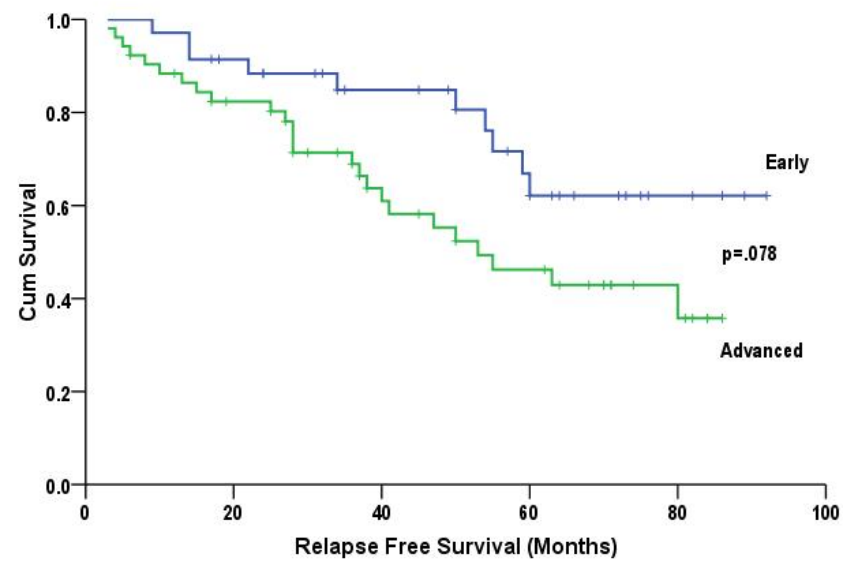

Figure 2: Downregulation of TGF- $\beta 1$ reduced relapse free survival in advanced stage patients than early stage patients.

concluding its role as a prognostic marker [14-16,18,19]. Circulatory TGF- $\beta 1$ was higher in breast cancer patients than controls. Moreover, serum TGF- $\beta 1$ was elevated in advanced stage than early stage patients. High TGF- $\beta 1$ was also connected to aggressive clinicopathologic prognosticators stamping its role in the progression and metastasis and was also associated with the reduced survival of the patients. These conclusions were drawn in our previous study [13]. In our previous study we had used the same patient's cohort and estimated circulating serum TGF- $\beta 1$. We have compared the results and found that protein and mRNA of TGF- $\beta 1$ did not correlate. This was also reported by $\mathrm{Mu}$ et al. $[13,28]$. Our previous study also reported higher circulating TGF- $\beta 1$ in breast cancer patients than healthy individuals where TGF- $\beta 1$ was higher in advanced stage than early stage patients. Elevated serum TGF- $\beta 1$ was also shown to be linked to aggressive clinicopathological prognosticators and reduced relapse free survival of the breast cancer patients [13]. 


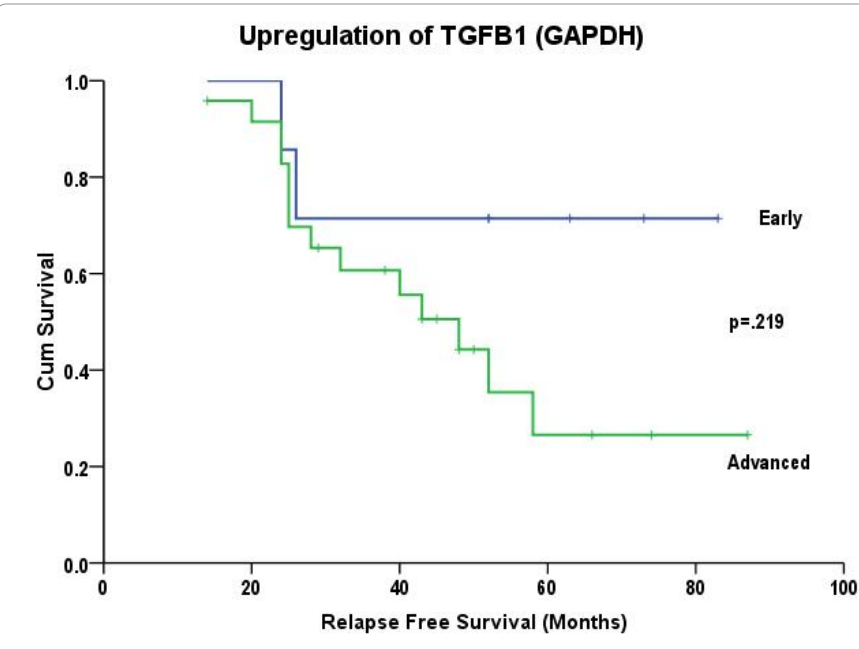

Figure 3: Upregulation of TGF- $\beta 1$ exhibited no different relapse free survival.

Gorsch et al. [29] demonstrated the immunohistochemical staining of all three TGF- $\beta$ isoforms in breast cancer to see the impact from any one of them on disease progression and found that TGF- $\beta_{1}$ staining was connected to the disease aggressiveness. In a study by Ghellal et al. [30] strong association of tumoral TGF- $\beta 1$ immunostaining was connected to tumor progression, reduced overall survival and an inverse correlation with lymph node involvement. Soufla et al. [23] have shown the transcriptional deregulation of TGF- $\beta$ ligands and their receptors by PCR and western blot analysis where a significant negative correlation was observed between TGF- $\beta 1$ protein and mRNA by breast tissue-pair analysis.

TGF- $\beta 1$ mRNA expression with real time PCR has been less explored from clinical human breast cancer samples [31]. Transcripts of TGF- $\beta$ isoforms have been explored in laryngeal cancer by Karpral et al. [25] who reported its usefulness to demarcate between neoplatic and nonneoplastic tissues. However, in the present study, TGF- $\beta 1$ transcript was detectable in all breast tumors. A significant downregulation of TGF- $\beta 1$ was evident in $73.73 \%$ patients when compared to respective normal tissues from each patient. To best our knowledge, this is the first study demonstrating a downregulation of TGF- $\beta 1$ using normal tissue as a calibrator and GAPDH as endogenous control from human breast tumors.

Majority of patients exhibited advanced stage and an aggressive disease. There were $99 \%$ tumors with more than $2 \mathrm{cms}$ tumor size and $58.1 \%$ patients with $>4$ positive lymph nodes. The patients therefore were grouped into early- and advanced- tumors for further analysis. A significantly different TGF- $\beta 1$ expression was seen amongst earlyand advanced-stage tumors; advanced stage tumors exhibited a higher magnitude of gene expression $(+4.08$ to -2.18 fold) than early tumors (+2.03 to -2.42 fold). This indicates a higher involvement of TGF- $\beta 1$ as the stage advances. This finding is consistent with the dual role of TGF- $\beta$ in breast tumorigenesis, better known as 'TGF- $\beta$ switch' [32].

Around $80 \%$ breast tumors originate in ducts and IDC is the most common, aggressive phenotype. We found a significantly lesser downregulation of TGF- $\beta 1$ in IDC and thus it was shown to be connected to an aggressive phenotype. Similarly, well differentiated tumors had lower upregulation of TGF- $\beta 1$ gene expression; this again suggested that TGF- $\beta 1$ was connected to an aggressive histologic type.
Degree of stromal reaction is the histologic criterion of reactivity of stroma to the growing tumor and connected to a favorable prognosis. We found a significant reduction in TGF- $\beta 1$ expression with presence of stromal reaction; connected to a possibility of better prognosis. Presence of tumor cells in axillary lymph nodes is regarded as the strongest predictor of aggressive disease that confers a poor prognosis. We observed a reduction in TGF- $\beta 1$ in malignant lymph nodes as compared to primaries. Thus, reduced TGF- $\beta 1$ expression was seen with an advancement of disease.

Moreover, this study offered us an opportunity to compare TGF- $\beta 1$ expression in non-malignant- and malignant- lymph nodes. We found that $86.3 \%$ non-malignant lymph nodes showed upregulation of TGF- $\beta 1$. It is hypothesized that 'such non-malignant' lymph nodes may harbor 'occult metastases'. If proven, the breast cancer patients with upregulated TGF- $\beta 1$ expression in non-malignant lymph nodes may become candidates for aggressive monitoring and subsequent therapeutic intervention with anti TGF- $\beta$ strategies.

In the current study, we found a down regulation of TGF- $\beta 1$ transcript and an upregulation in advanced human breast tumors independent of ERa up- or down- regulation. This unique finding may suggest a possibility of identifying such patients as candidates for anti TGF- $\beta$ strategies.

\section{Conclusion}

This is the first study that reports TGF- $\beta 1$ gene expression from a large cohort of Indian breast cancer patients that demonstrate its prognostic and predictive utility. 'TGF- $\beta 1$ switch' was evident; however, downregulation was associated with a reduced relapse free survival of breast cancer patients.

\section{Acknowledgement}

The study was partly supported by the funding from Indian Council of Medical research (Indo-German collaborative project) and The Gujarat Cancer Society, Ahmedabad, India.

\section{Ethical Committee Approval}

All procedures were approved by the institutional ethics committee and informed consent was obtained from all subjects.

\section{Conflict of interest statement}

None of the authors have any conflict of interest related to this manuscript.

\section{References}

1. Massague J (1998) TGF-beta Signal Transduction. Annu Rev Biochem 67 753-91

2. Lönn P, Morén A, Raja E, Dahl M, Moustakas A (2008) Regulating the stability of TGF $\beta$ receptors and Smads. Cell Res 19: 21-35

3. Barcellos-Hoff MH, Akhurst RJ (2009) Transforming growth factor-beta in breast cancer: too much, too late. Breast Cancer Res 11: 202-208.

4. Wakefield LM, Piek E, Böttinger EP (2001) TGF-beta signaling in mammary gland development and tumorigenesis. J Mammary Gland Biol Neoplasia 6 67-82.

5. Moses HL, Tucker RF, Leof EB, Coffey RJ, Halper J, et al. (1985) Type beta transforming growth factor is growth stimulator and a growth inhibitor. Cancer Cells 3: 65-71.

6. Roberts AB, Sporn MB, Assoian RK, Smith JM, Roche NS, et al. (1986) Transforming Growth factor type beta: Rapid induction of fibrosis and angiogenesis in vivo and stimulation of collagen formation in vitro. Proc Natl Acad Sci U S A 83: 4167-4171.

7. Derynck R, Feng XH (1997) TGF-beta receptor signaling; BBA Reviews in cancer 1333: F105-F150 
Citation: Dave HV, Shah MJ, Shukla SN, Trivedi SN (2011) Differential Gene Expression Pattern of Transforming Growth Factor Beta-1 in Early and Advanced Breast Cancers. J Cancer Sci Ther 3: 244-249. doi:10.4172/1948-5956.1000098

8. Frank S, Madlener M, Werner S (1996) Transforming b1, b2 and b3 and their receptors are differentially regulated during normal and impaired wound healing. J Biol Chem 271: 10188-10193.

9. Chang CF, Westbrook R, Ma J, Cao D (2007) Transforming growth factor-beta signaling in breast cancer. Front Biosci 12: 4393-4401.

10. Grau AM, Wen W, Ramroopsingh DS, Gao YT, Zi J, et al. (2008) Circulating transforming growth factor-b-1 and breast cancer prognosis: results from the Shanhgai Breast Cancer Study. Breast Cancer Res Treat 112: 335-341.

11. Shariat SF, Shalev M, Menesses-Diaz A, Kim IY, Kattan MW, et al. (2001) Preoperative plasma levels of transforming growth factor beta (1) (TGFbeta(1)) strongly predict progression in patients undergoing radical prostatectomy. $J$ Clin Oncol 19: 2856-2864.

12. Okumoto K, Hattori E, Tamura K, Kiso S, Watanabe H, et al. (2004) Possible contribution of circulating transforming growth factor-beta1 to immunity and prognosis in unresectable hepatocellular carcinoma. Liver Int 24: 21-28.

13. Dave H, Shah M, Trivedi S, Shukla S (2011) Prognostic utility of circulating transforming growth factor beta 1 in breast cancer patients Int $\mathrm{J}$ Biol Markers In Press.

14. Ivanović V, Demajo M, Krtolica K, Krajnović M, Konstantinović M, et al. (2006) Elevated plasma TGF-beta1 levels correlate with decreased survival of metastatic breast cancer patients. Clin Chim Acta 371: 191-193.

15. Ivanović V, Todorović-Raković N, Demajo M, Nesković-Konstantinović Z, Subota V, et al. (2003) Elevated plasma levels of transforming growth factorbeta1 (TGF-beta1) in patients with advanced breast cancer: associated with disease progression. Eur J Cancer 39: 454-446.

16. Ivanović V, Demajo M, Krtolica K, Krajnović M, Konstantinović M, et al. (2006) Elevated plasma TGF-beta1 levels correlate with decreased survival of metastatic breast cancer patients. Clin Chim Acta 37: 191-193.

17. Knabbe C, Kock A, Schmah M, Knust B, Dickson RB, et al. (1991) Regulation of TGF- beta1 and TGF- beta2 expression in MCF-7 cells. Annual meeting of the American Association for Cancer Research 32: 208.

18. Lebrecht A, Grimm C, Euller G, Ludwig E, Ulbrich E, et al. (2004) Transforming growth factor beta 1 serum levels in patients with preinvasive and invasive lesions of the breast. Int J Biol Markers 19: 236-239.

19. Nikolić-Vukosavljević D, Todorović-Raković N, Demajo M, Ivanović V, Nesković B, et al. (2004) Plasma TGF-b1-related survival of postmenopausal metastatic breast cancer patients. Clin Exp Metastasis 21: 581-585.

20. Koumoundourou D, Kassimatis T, Zolota V, Tzorakoeleftherakis E, Ravazoula
P, et al. (2007) Prognostic significance of TGFbeta-1 and pSmad2/3 in breas cancer patients with T1-2,N0 tumours. Anticancer Res 27: 2613-2620.

21. Walker RA, Dearing SJ, Gallacher B (1994) Relationship of transforming growth factor beta1 to extracellular matrix and stromal infiltrates in invasive breast carcinoma. Br J Cancer 69: 1160-1165

22. Li J, Zhu H, Chen T, Dai G, Zou L (2011) TGF beta1 and BRCA2 expression are associated with clinical factors in breast cancer. Cell Biochem Biophys 60 : 245-258

23. Soufla G, Porichis F, Sourvinos G, Vassilaros S, Spandidos DA (2006) Transcriptional deregulation of VEGF, FGF2, TGF-beta, 2, 3 and cognate receptors in breast tumorigenesis. Cancer Lett 235: 100-113.

24. Soufla G, Sifakis S, Baritaki S, Zafiropoulos A, Koumantakis E, et al. (2005) VEGF, FGF2, TGFB1 and TGFBR1 mRNA expression levels correlated with the malignant transformation of the uterine cervix. Cancer Lett 221: 105-118.

25. Kapral M, Strzalka B, Kowalczyk M, Jurzak M, Mazurek U, et al. (2008) Tramsfroming growth factor beta isoforms (TGF-beta1, TGF-beta2, TGFbeta3) messenger RNA expression in laryngeal cancer. Am J Otolaryngol 29 233-237.

26. Green FL, Page DL, Fleming ID (2002) AJCC Cancer Staging Manual. (6th edn), Chapter 25, Part VII, Breast. Germany: Springer-Verlag 221-240.

27. Schmittgen TD, Livak KJ (2008) Analyzing real-time PCR data by the comparative C(T) method. Nat Protoc 3: 1101-1108.

28. Mu L, Katsaros D, Lu L, Preti M, Durando A, et al. (2008) TGF-beta1 genotype and phenotype in breast cancer and their associations with IGFs and patient survival. Br J Cancer 99: 1357-1363.

29. Gorsch SM, Memoli VA, Stukel TA, Gold LI, Arrick BA (1992) Immunohistochemical Staining for Transforming Growth Factor beat 1 Associates with Disease Progression in Human Breast Cancer. Cancer Res 52: 6949-6952.

30. Ghellal A, Li C, Hayes M, Byrne G, Bundred N, et al. (2000) Prognostic Significance of TGF beta1 and TGF beta3 in human Breast Carcinoma Anticancer Res 20: 4413-4418.

31. Bierie B, Chung CH, Parker JS, Stover DG, Cheng N, et al. (2009) Abrogation of TGF-beta signaling enhances chemokine production and correlates with prognosis in human breast cancer. J Clin Invest 119 : 1571-1582.

32. Muraoka-Cook RS, Dumont N, Arteaga CL (2005) Dual Role of Transforming Growth Factor beta in Mammary Tumorigenesis and Metastatic Progression. Clin Cancer Res 11: 937s-943s. 